\title{
UPDATING MAPS USING HIGH RESOLUTION SATELLITE IMAGERY
}

\author{
Muhamad Alrajhi, Khurram Shahzad Janjua, Mohammad Afroz Khan, Abdalla Alobeid \\ Dept. of Surveying and Mapping,Ministry of Municipal and Rural Affairs, Riyadh Olaya KSA \\ alrajhi@momra.gov.sa \\ CommissionIV, WG IV/2
}

KEY WORDS: Change detection, Urban maps, Remote sensing, Building extraction, High Resolution Satellite Imagery, Planning / Decision support system

\begin{abstract}
:
Kingdom of Saudi Arabia is one of the most dynamic countries of the world. We have witnessed a very rapid urban development's which are altering Kingdom's landscape on daily basis. In recent years a substantial increase in urban populations is observed which results in the formation of large cities. Considering this fast paced growth, it has become necessary to monitor these changes, in consideration with challenges faced by aerial photography projects. It has been observed that data obtained through aerial photography has a lifecycle of 5-years because of delay caused by extreme weather conditions and dust storms which acts as hindrances or barriers during aerial imagery acquisition, which has increased the costs of aerial survey projects. All of these circumstances require that we must consider some alternatives that can provide us easy and better ways of image acquisition in short span of time for achieving reliable accuracy and cost effectiveness. The approach of this study is to conduct an extensive comparison between different resolutions of data sets which include: Orthophoto of $(10 \mathrm{~cm})$ GSD, Stereo images of (50cm) GSD and Stereo images of $(1 \mathrm{~m})$ GSD, for map updating. Different approaches have been applied for digitizing buildings, roads, tracks, airport, roof level changes, filling stations, buildings under construction, property boundaries, mosques buildings and parking places.
\end{abstract}

\section{INTRODUCTION}

Mapping has always been indispensable to the progress of humankind. In recent years remote sensing technology has been improved rapidly. This has influenced its related technologies too. These technologies have multidimensional applications from global-monitoring to personal global positioning systems (GPS). Comparatively remote sensing technology is not that much sophisticated or over-expensive gadgets that cannot be afforded or utilized, in recent scenario high resolution satellite sensors are already being used by mapping industries.

A study was initiated to find out if satellite imagery could replace or compliment aerial imagery in map updating production process with capacity building and system development to update exiting maps based on reliable or achievable accuracy and cost effective systems.

The Stereo satellite imageries are used to collect the required features from different map scales as per Ministry of Municipal and Rural Affairs (MOMRA) specifications. Hence, it was observed that for large scale mapping (1: 10,000, 1: 20,000), many of the features could be satisfactorily identified and captured but it could not achieve desired results in some other areas. However, in some cases it was very helpful to identify required features forsmall scale maps $(1: 1,000,1: 2,500)$.

During the current state of time it has been interpreted that high resolution satellite imageries are successfully used for quick data acquisition with reliable accuracies with high-quality for creating maps which include rasterized thematic and topographic to satisfy a variety of needs.

\subsection{Urban Populations Growth}

It has been studied that Kingdom of Saudi Arabia, covers an area of approximately 2,250,000 square kilo-meters and hence results in the significant growth of population ranging from $(30,000$ in 1940 s to 29.87 million) estimated in 2014 .

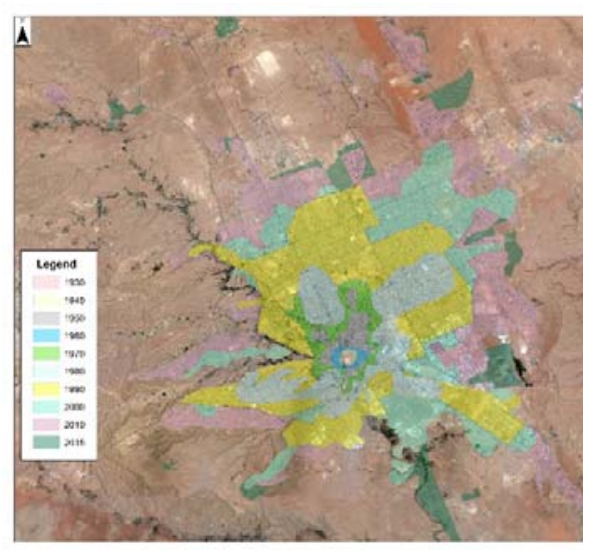

Figure 1 Riyadh Historical Growth

(Arriyadh Development Authority)

Thus substantial increase in urban populations and internal migration are some of the factors responsible for the rapid growth of cities, which directly affects quantity and quality of municipal services, which needs precise and quick map updates for developmental purpose. It can also help the government for responding demographic and infrastructure change requirements. Geospatial data is single most important factor in determining development needs of all municipal services and city planning.

\subsection{Kingdoms Environment}

Kingdom of Saudi Arabia is not different from rest of the world. However, different environmental conditions that exists in the Kingdom, imposes a major influence on weather conditions which intern affect radiometric conditions through many factors, such as different seasons, solar altitudes, sun angles, meteorological conditions and most importantly dust storms which some time cover complete cities etc. which creates hindrances to acquire images and caused delay in the projects. 


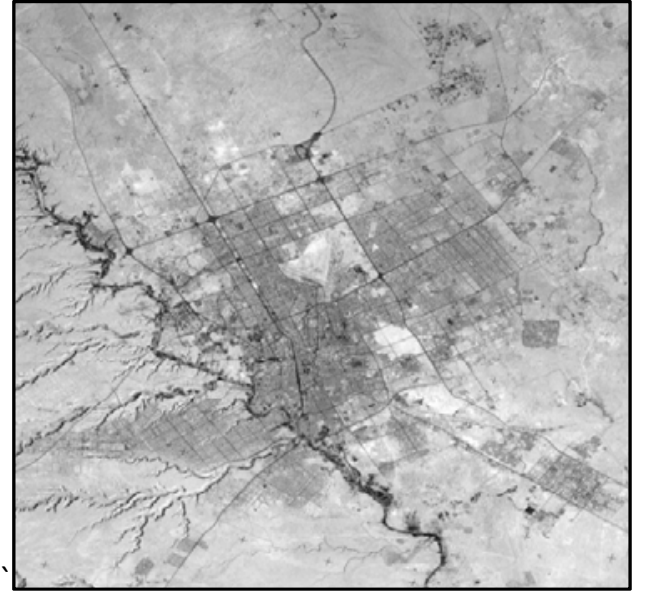

Figure 2a. Riyadh city

(Satellite Sensor: Ikonos, GSD:1m,Acquisition Date:2002)

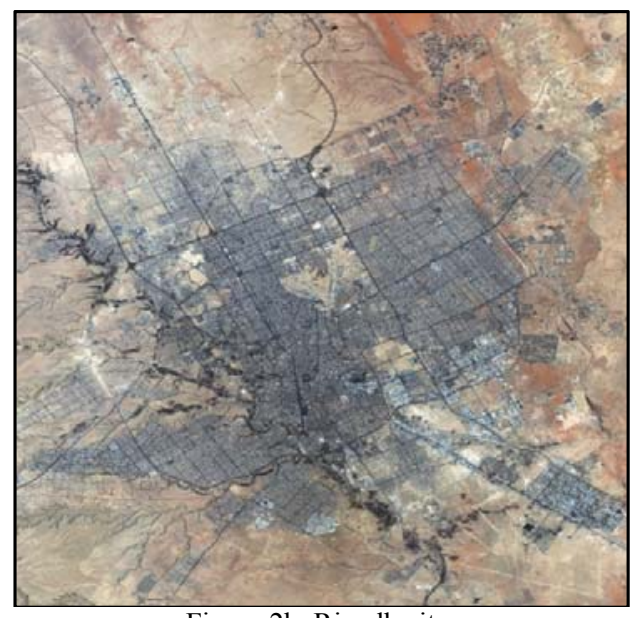

Figure 2b. Riyadh city

(Satellite Sensor: Ikonos, GSD:1m,Acquisition Date:2008)

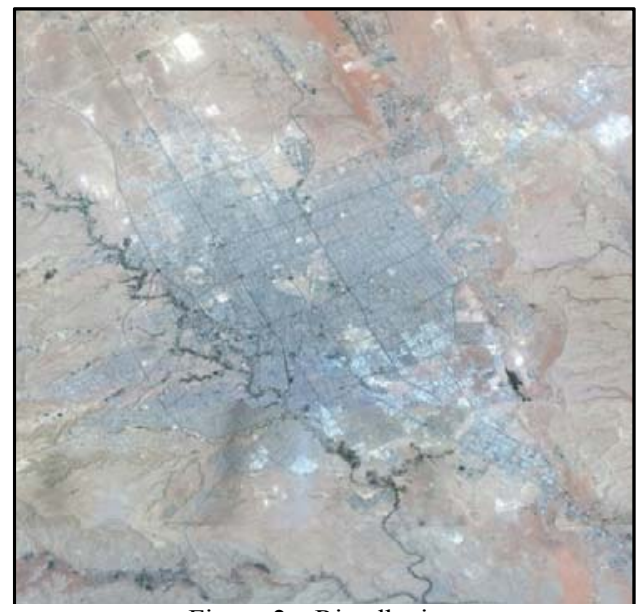

Figure 2c. Riyadh city

(Satellite Sensor: GeoEye, GSD:50cm, Acquisition Date:2014)

\section{STUDY AREA}

In this research paper, North of Riyadh area has been selected as current study area, to conduct a study on comparative methods of map updating. We have selected some features such as road- edges, road-paved, road-unpaved, miscellaneous structures, miscellaneous features, fence, filling stations, mosque, property boundary, building under construction and buildings that are required for multiple applications such as geodatabase creation and updating, city modelling and urban planning.

In Figure 2a showing satellite image of (satellite sensor: Ikonos, GSD: 1, Acquisition Date: 2002), Figure 2b satellite image of (satellite sensor: Ikonos, GSD: 1, Acquisition Date: 2008) and Figure 2c satellite image showing (Satellite Sensor: GeoEye, GSD: 50cm, Acquisition Date: 2014) one can easily observe significant changes over the years.

The growth of Riyadh, which is the national capital of Kingdom, observes a dramatic change in urban growth between the years 1972to 2013 (USGS, 2016), according to a report from (USGS) Riyadh's population was increased by about 10 percent, which results in population growth from about half million to over 5 million. The cities delineated drastic urban growth due to inmigration from rural areas.

\section{SATELLITE IMAGERY FOR MAP UPDATING}

Remote Sensing using satellite images offers facilities which are one of the most important modern-days inventions for data acquisition and primary methods of recording changes and monitoring objects from remote distances through devices which are equipped with multiband electromagnetic spectrum sensors.

High-resolution satellite imagery is commercially available at reasonable costs in various formats. Many agencies have shown their interest in utilization of satellite imagery in various programs for map updating.

Since, Saudi Arabia has large open area mostly occupied by deserts encompassing most of the Arabian Peninsula, with Red Sea and Persian Gulf coastlines which makes it difficult to reach some of remotely populated areas. Thus it is not economically viable to survey these areas through conventional means and convert it into maps. On the basis of these considerations our approach for utilizing the potential of high resolution satellite images to investigate the study area using available sensors having $(1 \mathrm{~m}$ to $0.5 \mathrm{~m}) \mathrm{GSD}$ of resolution. The results obtained encourage us to make use of different map scales between $1: 2,500$ and $1: 10,000$ in rural areas for interpreting changes.

\subsection{Image Registration}

Accurate spatial registration of satellite imageries is very important to avoid large errors and obtain positive results because specific registration of satellite imageries is essential for many change detection observations. During this research it was observed that in order to obtain better results, the geometrical corrections at precise sub-pixel levels required. However, some other conditions may arise and cause effects on change detection algorithms. Because, accuracy is affected by many factors, such as image angles including various conditions like curvatures and rotation of satellites. Precisely, in urban and mountainous regions general image registration methods become least effective and hence results in the Ortho-rectification of satellite or aerial imageries as a necessary part and parcel. 


\section{MAP UPDATION BY DIGITIZING STEREO SATELLITE IMAGERY}

The topography of Saudi Arabia is undulating and uneven thus the population development took place based on the terrain conditions which consists following major types for population growth which include:
1. Urban
2. Semi-urban
3. Rural

Our major concern is to update urban and semi-urban areas, especially major cities which are growing rapidly.

To manage municipal needs, it is very important to update maps more frequently because after every few months significant changes are observed in settlements. In the very beginning stage for updating maps process, orthorectification of satellite images have been conducted.

Some of the areas were examined to make sure that different types of settlements have been considered, by analyzing and comparing positional accuracies of aerial images and satellite imagery to evaluate the results.

In each of these areas, the features were captured as per MOMRA specifications at various mapping scales which include: $(1: 1,000$ scales for urban, $(1: 2500)$ scales for rural and $(1: 10,000)$ scales for mountainous areas. The feature data collected from these areas include: roads, tracks, buildings, and property boundaries.
In order to derive positive results, the topographic data for the year 2007 was used as a reference for conducting change detections. For 3D purpose data is extracted from satellite sensors of (50cm and $1 \mathrm{~m}$ GSD) with different images of year (2009), (2012) and (2014). For this reason, we have used commercially available tools from INPHO for Ortho-rectification with 10 meter DTM and (15 to 25$)$ ground control points in 10 sq.km area depending on different geographic conditions. 3D digitization is completed with DATUM system's Summit software. Results of this study are presented in this paper.

\subsection{Positional Accuracy Assessment between $50 \mathrm{~cm}$ and $1 \mathrm{~m}$ GSD Stereo Satellite Imagery with $10 \mathrm{~cm}$ GSD Orthophoto}

It is very obvious that change detection is influenced by many factors such as availability, accurate geometric registration, number of ground control points, and calibration of images, methods of algorithms, professional skills, expertise and above all time and cost related to it.

\subsection{Methodology}

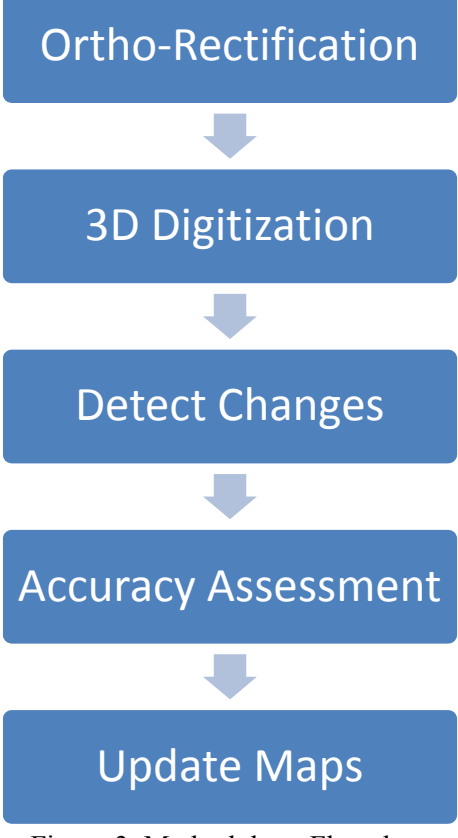

Figure 3. Methodology Flowchart 
The International Archives of the Photogrammetry, Remote Sensing and Spatial Information Sciences, Volume XLI-B4, 2016 XXIII ISPRS Congress, 12-19 July 2016, Prague, Czech Republic

4.3. Comparative Analyses of Satellite Sensors with Orthophoto

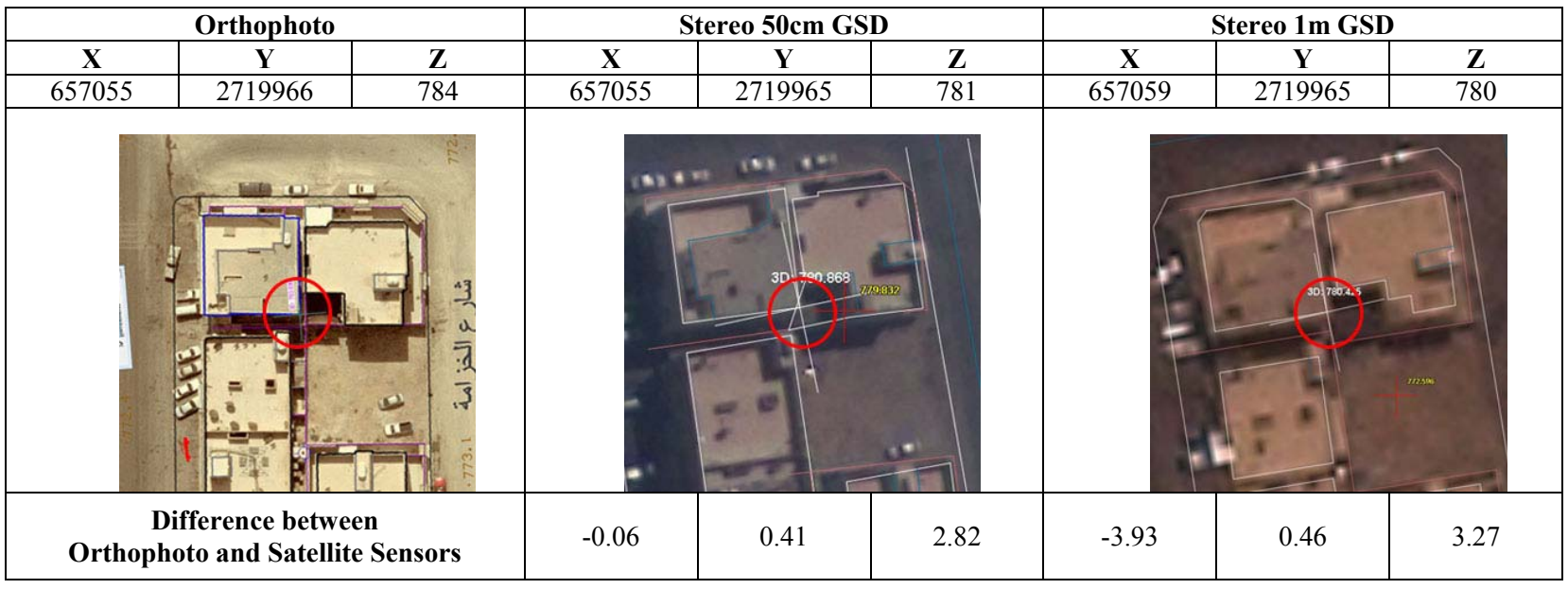

Table 1a. Showing capturing of building corner based on different resolutions of Stereopairs

\begin{tabular}{|c|c|c|c|c|c|c|c|}
\hline \multicolumn{2}{|c|}{ Orthophoto } & \multicolumn{2}{c|}{ Stereo 50cm GSD } & \multicolumn{3}{c|}{ Stereo 1m GSD } \\
\hline $\mathbf{X}$ & $\mathbf{Y}$ & $\mathbf{Z}$ & $\mathbf{X}$ & $\mathbf{Y}$ & $\mathbf{Z}$ & $\mathbf{X}$ & $\mathbf{Y}$ \\
\hline 656974 & 2719932 & 774 & 656972 & 2719933 & 772 & 656974 & 2719930 \\
\hline \\
\hline
\end{tabular}

Table 1.b showing capturing of road corner based on different resolutions of Stereopairs.

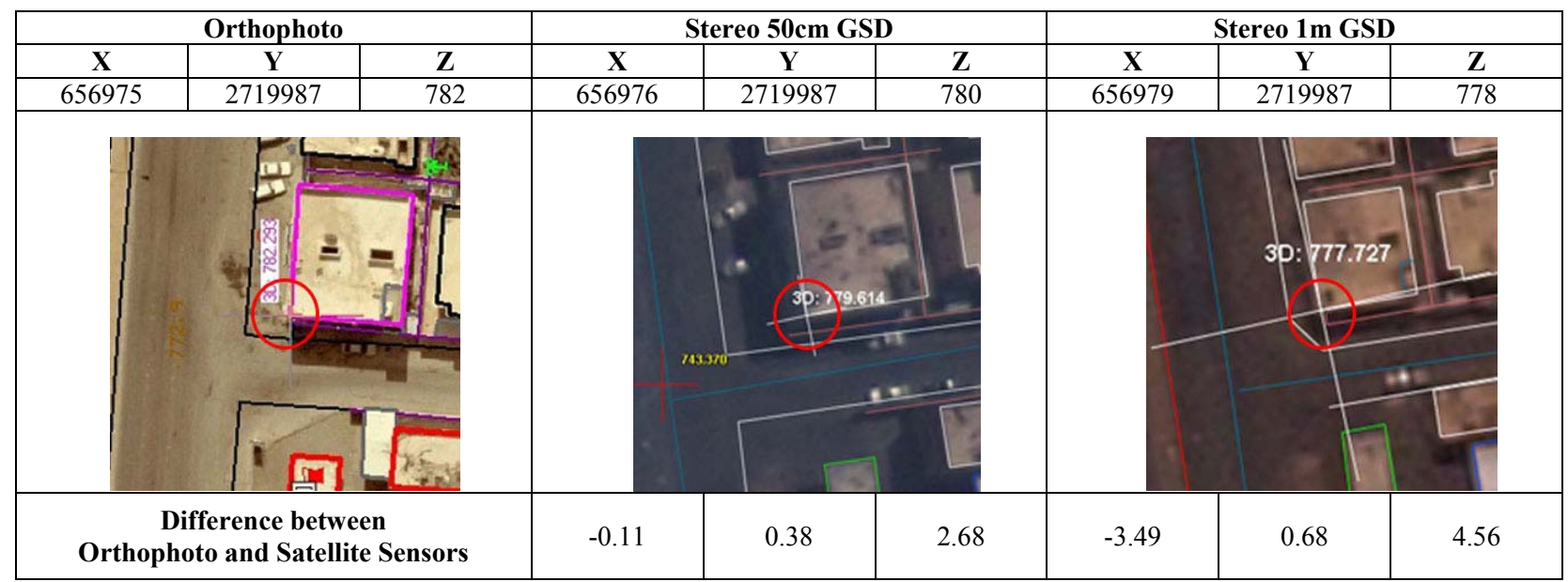

Table 1c. showing comparability between Orthophoto and Satellite imagery adjacent to road 


\begin{tabular}{|c|c|c|c|c|c|c|c|c|}
\hline \multicolumn{3}{|c|}{ Orthophoto } & \multicolumn{3}{c|}{ Stereo 50cm GSD } & \multicolumn{3}{c|}{ Stereo 1m GSD } \\
\hline $\mathbf{X}$ & $\mathbf{Y}$ & $\mathbf{Z}$ & $\mathbf{X}$ & $\mathbf{Y}$ & $\mathbf{Z}$ & $\mathbf{X}$ & $\mathbf{Y}$ & $\mathbf{Z}$ \\
\hline 656886 & 2719806 & 785 & 656886 & 2719805 & 781 & 656890 & 2719805 & 781 \\
\hline & & & & & & & & \\
\hline
\end{tabular}

Table 1d. showing comparability between Orthophoto and Satellite imagery adjacent to tree

\begin{tabular}{|c|c|c|c|c|c|c|c|c|}
\hline \multicolumn{2}{|c|}{ Orthophoto } & \multicolumn{3}{c|}{ Stereo 50cm GSD } & \multicolumn{3}{c|}{ Stereo 1m GSD } \\
\hline $\mathbf{X}$ & $\mathbf{Y}$ & $\mathbf{Z}$ & $\mathbf{X}$ & $\mathbf{Y}$ & $\mathbf{Z}$ & $\mathbf{X}$ & $\mathbf{Y}$ & $\mathbf{Z}$ \\
\hline 656901.42 & 2719992.86 & 779.37 & 656901.7754 & 2719992.263 & 776.604 & 656905.7492 & 2719992.434 & 775.3 \\
\hline & & & & & & \\
\hline
\end{tabular}

Table 1e. showing capturing of building corner based on different resolutions of Stereopairs.

\begin{tabular}{|c|c|c|c|c|c|c|c|c|}
\hline \multicolumn{3}{|c|}{ Orthophoto } & \multicolumn{3}{c|}{ Stereo 50cm GSD } & \multicolumn{3}{c|}{ Stereo 1m GSD } \\
\hline $\mathbf{X}$ & $\mathbf{Y}$ & $\mathbf{Z}$ & $\mathbf{X}$ & $\mathbf{Y}$ & $\mathbf{Z}$ & $\mathbf{X}$ & $\mathbf{Y}$ & $\mathbf{Z}$ \\
\hline 656915.06 & 2719956.65 & 784.079 & 656914.2654 & 2719956.34 & 781.102 & 656917.6164 & 2719957.74 & 779.5 \\
\hline & & & & & & & & \\
\hline
\end{tabular}

Table 1f. showing capturing of building corner based on different resolutions of Stereopairs 


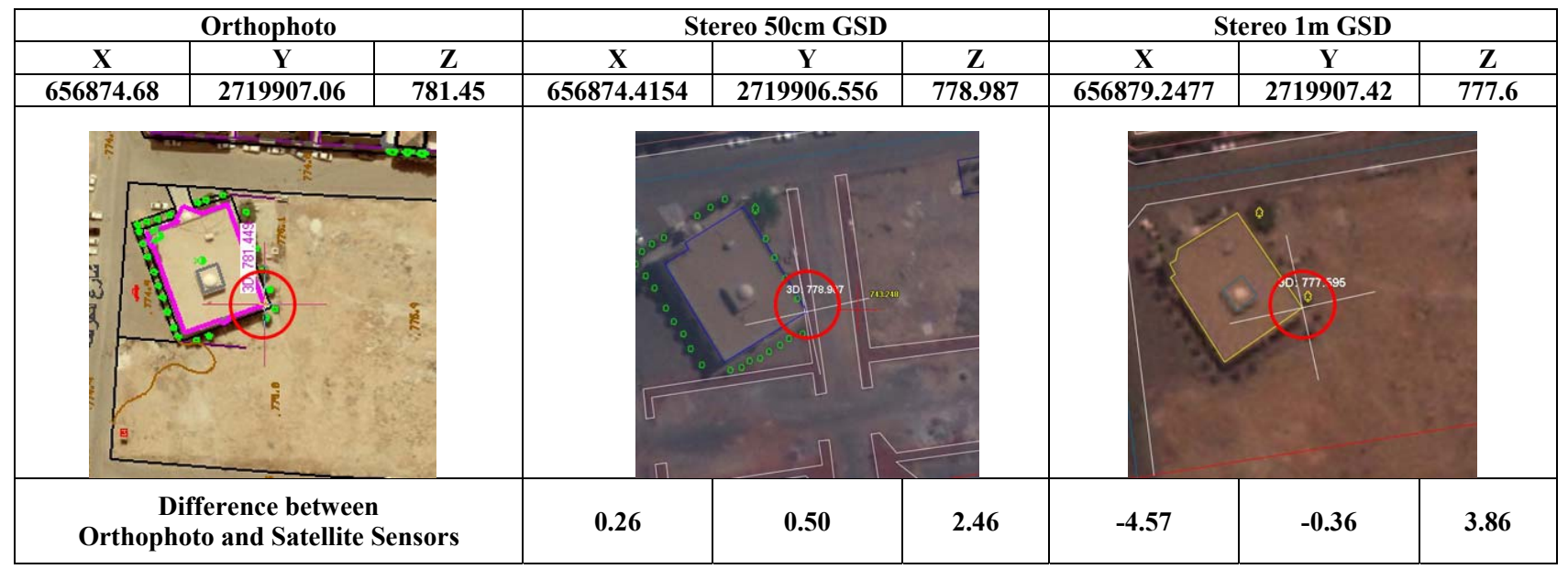

Table 1g. Showing the example of mosque building which is recognizable on $50 \mathrm{~cm}$ and $1 \mathrm{~m}$ GSD Stereo Satellite Imagery but $10 \mathrm{~cm}$ GSD orthophoto have more details of the mosque building

\begin{tabular}{|c|c|c|c|c|c|c|c|c|}
\hline \multicolumn{2}{c}{ Orthophoto } & \multicolumn{3}{c|}{ Stereo 50cm GSD } & \multicolumn{3}{c|}{ Stereo 1m GSD } \\
\hline $\mathbf{X}$ & $\mathbf{Y}$ & $\mathbf{Z}$ & $\mathbf{X}$ & $\mathbf{Y}$ & $\mathbf{Z}$ & $\mathbf{X}$ & $\mathbf{Y}$ & $\mathbf{Z}$ \\
\hline 656945.13 & 2719981.59 & 777.751 & 656945.2251 & 2719980.974 & 775.384 & 656948.1725 & 2719981.318 & 774.4 \\
\hline & & & & & \\
\hline
\end{tabular}

Table 1h. Showing capturing of building corner based on different resolutions of Stereopairs.

\begin{tabular}{|c|c|c|c|c|c|c|c|c|}
\hline \multicolumn{3}{c|}{ Orthophoto } & \multicolumn{3}{c|}{ Stereo 50cm GSD } & \multicolumn{3}{c|}{ Stereo 1m GSD } \\
\hline $\mathbf{X}$ & $\mathbf{Y}$ & $\mathbf{Z}$ & $\mathbf{X}$ & $\mathbf{Y}$ & $\mathbf{Z}$ & $\mathbf{X}$ & $\mathbf{Y}$ & $\mathbf{Z}$ \\
\hline 656927.53 & 2719803.19 & 785.115 & 656927.4508 & 2719802.643 & 782.455 & 656931.6033 & 2719803.019 & 781.1 \\
\hline
\end{tabular}

Table 1i. Showing capturing of building corner based on different resolutions of Stereopairs. 


\begin{tabular}{|c|c|c|c|c|c|c|c|c|}
\hline \multicolumn{3}{|c|}{ Orthophoto } & \multicolumn{3}{c|}{ Stereo 50cm GSD } & \multicolumn{3}{c|}{ Stereo 1m GSD } \\
\hline $\mathbf{X}$ & $\mathbf{Y}$ & $\mathbf{Z}$ & $\mathbf{X}$ & $\mathbf{Y}$ & $\mathbf{Z}$ & $\mathbf{X}$ & $\mathbf{Y}$ & $\mathbf{Z}$ \\
\hline 656911.15 & 2719836.04 & 784.911 & 656911.1971 & 2719835.247 & 783.386 & 656911.5884 & 2719836.066 & 780.8 \\
\hline
\end{tabular}

Table $1 \mathrm{j}$. Showing capturing of building corner based on different resolutions of Stereopairs.

Comparative Analyses of 50cm GSD and 1m GSD Stereo Satellite Imagery with Orthophoto

\begin{tabular}{|c|c|c|c|c|c|c|c|c|c|c|c|c|c|c|c|}
\hline \multirow[b]{2}{*}{ No. } & \multicolumn{3}{|c|}{ Orthophoto $10 \mathrm{~cm}$ GSD } & \multicolumn{3}{|c|}{ Stereo $50 \mathrm{~cm}$ GSD } & \multicolumn{3}{|c|}{ Stereo 1m GSD } & \multicolumn{3}{|c|}{ Stereo $50 \mathrm{~cm}$ GSD } & \multicolumn{3}{|c|}{ Stereo 1m GSD } \\
\hline & $\mathbf{X}$ & $\mathbf{Y}$ & $\mathbf{Z}$ & $\mathbf{X}$ & $\mathbf{Y}$ & $\mathbf{Z}$ & $\mathbf{X}$ & $\mathbf{Y}$ & $\mathbf{Z}$ & $\begin{array}{c}\mathbf{X} \\
\text { Delta }\end{array}$ & $\begin{array}{c}\text { Y } \\
\text { Delta }\end{array}$ & $\begin{array}{c}\text { Z } \\
\text { Delta }\end{array}$ & $\begin{array}{c}\mathbf{X} \\
\text { Delta }\end{array}$ & $\begin{array}{c}\text { Y } \\
\text { Delta }\end{array}$ & $\begin{array}{c}Z \\
\text { Delta }\end{array}$ \\
\hline 1 & 657054.68 & 2719965.58 & 783.69 & 657054.74 & 2719965.17 & 780.87 & 657058.61 & 2719965.12 & 780.43 & -0.06 & 0.41 & 2.82 & -3.93 & 0.46 & 3.27 \\
\hline 2 & 656973.72 & 2719932.23 & 773.81 & 656972.06 & 2719933.47 & 771.70 & 656974.27 & 2719929.78 & 770.92 & 1.66 & -1.24 & 2.10 & -0.55 & 2.45 & 2.89 \\
\hline 3 & 656975.49 & 2719987.33 & 782.29 & 656975.60 & 2719986.95 & 779.61 & 656978.98 & 2719986.65 & 777.73 & -0.11 & 0.38 & 2.68 & -3.49 & 0.68 & 4.56 \\
\hline 4 & 656885.72 & 2719805.53 & 784.63 & 656885.52 & 2719805.04 & 781.38 & 656889.53 & 2719804.75 & 780.83 & 0.20 & 0.49 & 3.24 & -3.81 & 0.78 & 3.79 \\
\hline 5 & 656901.42 & 2719992.86 & 779.37 & 656901.78 & 2719992.26 & 776.60 & 656905.75 & 2719992.43 & 775.32 & -0.36 & 0.60 & 2.77 & -4.33 & 0.43 & 4.05 \\
\hline 6 & 656915.06 & 2719956.65 & 784.08 & 656914.27 & 2719956.34 & 781.10 & 656917.62 & 2719957.74 & 779.46 & 0.79 & 0.31 & 2.98 & -2.56 & -1.09 & 4.62 \\
\hline 7 & 656874.68 & 2719907.06 & 781.45 & 656874.42 & 2719906.56 & 778.99 & 656879.25 & 2719907.42 & 777.60 & 0.26 & 0.50 & 2.46 & -4.57 & -0.36 & 3.86 \\
\hline 8 & 656945.13 & 2719981.59 & 777.75 & 656945.23 & 2719980.97 & 775.38 & 656948.17 & 2719981.32 & 774.37 & -0.10 & 0.62 & 2.37 & -3.04 & 0.27 & 3.38 \\
\hline 9 & 656927.53 & 2719803.19 & 785.12 & 656927.45 & 2719802.64 & 782.46 & 656931.60 & 2719803.02 & 781.14 & 0.08 & 0.55 & 2.66 & -4.07 & 0.17 & 3.97 \\
\hline 10 & 656911.15 & 2719836.04 & 784.91 & 656911.20 & 2719835.25 & 783.39 & 656911.59 & 2719836.07 & 780.84 & -0.05 & 0.79 & 1.52 & -0.44 & -0.03 & 4.07 \\
\hline & & & & & & & & \multicolumn{2}{|c|}{ AVERAGE } & 0.23 & 0.34 & 2.56 & -3.08 & 0.38 & 3.85 \\
\hline & & & & & & & & \multicolumn{2}{|c|}{ STDEV } & 0.59 & 0.57 & 0.48 & 1.48 & 0.91 & 0.55 \\
\hline
\end{tabular}

Table 2.Showingsummary results

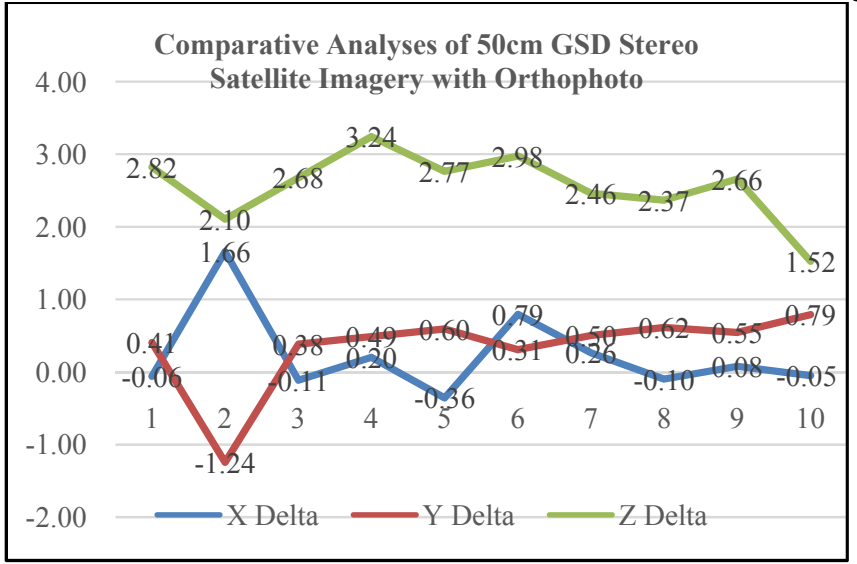

Figure 2. Comparative analyses of data digitized from $50 \mathrm{~cm}$ GSD Stereo Satellite Imagery with $10 \mathrm{~cm}$ GSD Orthophoto

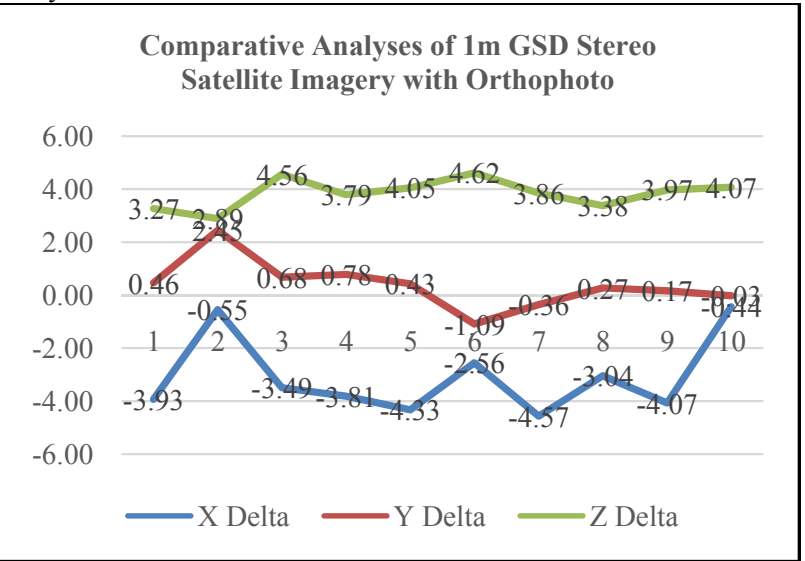

Figure 2 Comparative analyses of data digitized from 1m GSD Stereo Satellite Imagery with $10 \mathrm{~cm}$ GSD Orthophoto 
The results acquired for map updating in case of Stereo images with $(1 \mathrm{~m})$ GSD delineates that interpretations are not workable at $1 \mathrm{~K}$ scale and in certain areas at $2.5 \mathrm{~K}$ scale. Hence from the observed results and on the basis of this current research it is recommended that switching to higher resolutions of Stereo images with $(50 \mathrm{~cm})$ or lesser GSD will give us desired results at a faster rate and short span of time.

\section{CONCLUSION}

All thought aerial imagery have its own advantages and satellite imagery is no ware near to replace them but they result provide enough reliability and accuracy that we can user to update maps.

The results obtained from $50 \mathrm{~cm}$ GSD satellite images provide promisingresults. It was noted that most of the features required for (1:2,500 - 1:10,000 mapping scale) could have been reasonably identified and captured. At the same time, features mandatory for large scale mapping such as roads, buildings could have easily been identified. However; it was very difficult to identify features for those areas which are not clear.

Our findings are as following:

\begin{tabular}{|c|c|c|c|c|c|c|c|c|c|}
\hline \multirow{2}{*}{ Features } & \multicolumn{3}{|c|}{$\begin{array}{c}\text { Orthophoto } 10 \mathrm{~cm} \\
\text { GSD }\end{array}$} & \multicolumn{3}{|c|}{ Stereo $50 \mathrm{~cm}$ GSD } & \multicolumn{3}{|c|}{ Stereo 1m GSD } \\
\hline & $\begin{array}{l}\mathbf{1} \\
\mathbf{K}\end{array}$ & $\begin{array}{c}2.5 \\
\text { K }\end{array}$ & $\begin{array}{l}10 \\
K\end{array}$ & $\begin{array}{l}1 \\
\mathbf{K}\end{array}$ & $\begin{array}{c}2.5 \\
\mathrm{~K}\end{array}$ & $\begin{array}{l}10 \\
K\end{array}$ & $\begin{array}{l}1 \\
\mathbf{K}\end{array}$ & $\begin{array}{c}2.5 \\
\text { K }\end{array}$ & $\begin{array}{l}10 \\
\mathrm{~K}\end{array}$ \\
\hline Buildings & $\checkmark$ & $\checkmark$ & $\checkmark$ & $x$ & $x$ & $\checkmark$ & $x$ & $x$ & $\checkmark$ \\
\hline Roads & $\checkmark$ & $\checkmark$ & $\checkmark$ & $\checkmark$ & $\checkmark$ & $\checkmark$ & $x$ & $x$ & $\checkmark$ \\
\hline Tracks & $\checkmark$ & $\checkmark$ & $\checkmark$ & $x$ & $x$ & $\checkmark$ & $x$ & $x$ & $x$ \\
\hline Airport & $\checkmark$ & $\checkmark$ & $\checkmark$ & $x$ & $x$ & $\checkmark$ & $x$ & $x$ & $\checkmark$ \\
\hline Street lights & $\checkmark$ & $\checkmark$ & $\checkmark$ & $\checkmark$ & $\checkmark$ & $\checkmark$ & $x$ & $x$ & $x$ \\
\hline $\begin{array}{l}\text { Roof Level } \\
\text { Change }\end{array}$ & $\checkmark$ & $\checkmark$ & $\checkmark$ & $\checkmark$ & $\checkmark$ & $\checkmark$ & $x$ & $x$ & $\checkmark$ \\
\hline $\begin{array}{l}\text { Filling } \\
\text { Stations }\end{array}$ & $\checkmark$ & $\checkmark$ & $\checkmark$ & $\checkmark$ & $\checkmark$ & $\checkmark$ & $\checkmark$ & $\checkmark$ & $\checkmark$ \\
\hline $\begin{array}{l}\text { Buildings } \\
\text { Under } \\
\text { Constructio } \\
\text { n }\end{array}$ & $\checkmark$ & $\checkmark$ & $\checkmark$ & $\checkmark$ & $\checkmark$ & $\checkmark$ & $\checkmark$ & $\checkmark$ & $\checkmark$ \\
\hline $\begin{array}{l}\text { Property } \\
\text { Boundary }\end{array}$ & $\checkmark$ & $\checkmark$ & $\checkmark$ & $x$ & $\checkmark$ & $\checkmark$ & $x$ & $x$ & $\checkmark$ \\
\hline $\begin{array}{l}\text { Mosque } \\
\text { Buildings }\end{array}$ & $\checkmark$ & $\checkmark$ & $\checkmark$ & $\checkmark$ & $\checkmark$ & $x$ & $\checkmark$ & $\checkmark$ & $\checkmark$ \\
\hline Parking & $\checkmark$ & $\checkmark$ & $\checkmark$ & $\checkmark$ & $\checkmark$ & $\checkmark$ & $x$ & $x$ & $\checkmark$ \\
\hline
\end{tabular}

Table 10 showing list of features for map updation at different scales
Comparative analysis shows that there is no significant difference between most of the features obtained from Orthophoto of $(10 \mathrm{~cm}$ GSD) and Stereo images of (50 cm GSD) satellite imagery. However, using 0.5 meter GSD satellite images or less has certain advantages over 1 meter GSD.

\subsection{Advantages of Using 0.5 meter GSD or less}

- $\quad$ Required features are clearly identified

- $\quad$ Building shapes can be identified

- Under construction sites are easy to detect

- Residential and industrial buildings are easily being identified

- Difficult areas are easily mapped

- Imagery is available more rapidly

- Wide-area of coverage

\subsection{Disadvantages of Using 1 meter GSD}

- Some features are not clearly identified

- $\quad$ Some building shapes are not identified

- Sometime under construction sites are not identified

- Tracks are not clear

- Complex shapes and multilevel structures are very difficult to capture

- Image resolution is not good enough to differentiate between buildings

- All small linear features are difficult to see (e.g. fences, paths, or property boundaries).

\section{RECOMMENDATIONS}

The usage of more sophisticated and advanced remote sensing technology solutions to provide reliable and inexpensive information that can be employed for map updating. Improved satellite-based remote sensing instruments with less than $(50 \mathrm{~cm})$ GSD is the new frontiers in mapping, environmental, and ecological data analysis. Satellite imagery can be used to update mid-scale maps for urban change detections up to $2,5 \mathrm{k}$ particularly when satellite sensors have less than $50 \mathrm{~cm}$ GSD. The results become more accurate and more features can be captured with better perception.

However, in each case there are some advantages and disadvantages which indicate that $50 \mathrm{~cm}$ or lesser GSD satellite imagery should be used for updating maps.

\section{ACKNOWLEDGMENTS:}

The authors would like to extend their sincere appreciation to the Ministry of Municipal and Rural Affairs for support of this research. 


\section{REFERENCES}

Gong J., Sui H., Guoruia M.\& Zhou Q. (2008): A Review Of Multi-Temporal Remote Sensing Data Change Detection AlgorithmsIn: Vol. XXXVII. Part B7. Beijing

David H. (2004): Updating Maps In A Well-Mapped Country Using High Resolution Satellite Imagery In: XXXV, ISSN 16821750 p. 226

Jacobsen, K.; Alobeid, A. (2011): Monitoring of Buildings based on GeoEye-1, IKONOS and aerial image stereo pairs. In: 31 st EARSel symposium, Prague, 2011, 8 S., CD + EARSeL Newsletter, No. 86, pp. 20-26

Grodecki, J., Dial, G., Lutes, J. (2003): Error propagation in block adjustment of high-resolution satellite images. In: ASPRS Annual Mtg, Anchorage, p.10

Delacourt C., Allemand, P., Berthier, E., Raucoules, D., Casson, B., Grandjean, P., Pambrun, C., Varel, E., (2007): Remotesensing techniques for analysing landslide kinematics: In: A review. Bulletin de la Societe Geologique de France, 178(2) pp.89-100.

Fraser, C.S., Hanley, H.B. \&Yamakawa, T.(2002): Threedimensional, geopositioning accuracy of IKONOS imagery.In: Photogrammetric Record, 17 (99) pp.465-479.

Wenzhong S.\& Shaker A. (2003):Analysis of Terrain Elevation Effects on Ikonos Imagery Rectification Accuracy by Using NonRigorous Models In:Photogrammetric Engineering \& Remote Sensing p.1359

Rashad A.E. , Gamal L.E.T(2011): assessment of cartographic potential of EgyptSat-1 satellite image (case study in flat areas) In: Applied Geomatics 3(3) p.159-169.

Hamad n. Alsaiari, dr. Eric d. (2010): Urban Sprawl In Desert Cities: The Case Studies Of Phoenix, Arizona And Riyadh, Saudi Arabia In: Ball State University, Muncie, Indiana,

Oriental Institute Computer Laboratory

(http://oi.uchicago.edu/research/computer-laboratory/remotesensingsatellite-imaging, Accessed in 2016).

Urbanization: Riyadh, Saudi

Arabia,(http://www.jpl.nasa.gov/spaceimages/details.php?id=PIA

11087, Accessed in 2016)

USGS (http://earthshots.usgs.gov/earthshots/Riyadh, Accessed in 2016) 